\title{
A Comparative In-Vitro Study of Sealing Ability of Four Different Materials Used in Furcation Perforation
}

\author{
Georgia E. Nikoloudaki, Taxiarchis Kontogiannis, Helen A. Meliou, Nikolaos P. Kerezoudis \\ Department of Endodontics, Dental School, University of Athens, Athens, Greece \\ Email: nikgogo@dent.uoa.gr
}

Received 7 June 2014; revised 22 July 2014; accepted 2 August 2014

Copyright (C) 2014 by authors and Scientific Research Publishing Inc.

This work is licensed under the Creative Commons Attribution International License (CC BY). http://creativecommons.org/licenses/by/4.0/

(c) (i) Open Access

\section{Abstract}

The purpose of this study was to compare the sealing ability and marginal adaptation of four restorative materials (MTA, Biodentine, portlant cement, and resin modified glass ionomer cement) used to repair iatrogenic furcation perforations. Eighty-four molars were treated endodontically, perforated in the middle of the pulp chamber floor with a round bur and separated randomly into 4 groups of 20 teeth each, while 4 teeth were used as positive and negative controls. The teeth were embedded in a moistened flower sponge and the perforations were filled with the appropriate restorative materials: Group 1: Biodentine; Group 2: MTA Angelus; Group 3: GC Fuji lining LC Paste Pak; Group 4: Aquafix Portland cement. The teeth remained in the soaked sponge for 28 days and then were submerged in basic fuchsine solution $1 \%$ for 48 hours. Dye penetration was evaluated after longitudinal sectioning of the teeth. Statistical analysis revealed that perforations restored with MTA exhibited the least microleakage with statistically significant difference among the other three groups $(p<0.05)$. The worst sealing ability was observed in the teeth restored with Aquafix Portland cement. No statistically significant difference was found between the groups of Biodentine and FC Fuji Lining Paste $(p=0.066)$.

\section{Keywords}

MTA, Biodentine, Resin Modified Glass Ionomer Cement, Dye Microleakage

\section{Introduction}

Perforation is a pathological communication between the root canal system and the surrounding periodontal tissues. It may be caused during a pathological process such as caries, internal/external resorption or it may occur 
at any time during endodontic treatment or during post placement. However, perforation of the furcation area occurs more often during the access preparation in an effort to locate a root canal orifice. Long-term prognosis of this complication is dependent on many factors, such as the location and size of perforation, the time delay prior to perforation repair, the previous contamination by microorganisms, the sealing ability of the restorative material and the periodontal status of the tooth [1] [2]. Perforations in the furcal area are treated conservatively or surgically. The most favorable prognosis seems to have the nonsurgical intermediate repair with an appropriate restorative material which will prevent the communication of the pulp chamber with the gingival sulcus thus limiting the contamination and inflammation in this area [3]. It is widely accepted that such a material should have exceptional physiochemical and mechanical properties and biocompatibility [4] [5].

During the past decades many materials have been used for this purpose, including amalgam, Cavit [6], IRM, Super-EBA [7], glass ionomer cements and resins [8]. Among them, the use of Mineral Trioxide Aggregate (MTA) has been clearly suggested by most clinicians due to its sealing ability [9], marginal adaptation [10] and biocompatibility [4] [5] [11] [12] based on cytotoxicity and genotoxicity tests on cells cultures, implantation tests and usage tests in experimental animals. However, MTA exhibits the disadvantages of extended initial setting time (3 - 4 hours) [13], difficulty in handling (depending on the water/powder ratio) and high cost.

In order to overcome these disadvantages, a new material, Biodentine, has been recently released in the market. According to its manufacturer [14], it seems to have similar physiochemical, mechanical, biological properties to MTA but shorter setting time (9 - 12 minutes) [15] without any aluminate or calcium sulfate in its composition. Regarding the fact that teeth are unavoidably subjected to masticatory stress forces, a recent study, evaluating the dislodgement resistance of different sealing materials used in furcal perforations, proposes that Biobentine's push-out bone strength is not affected by blood contamination and that MTA have significantly less push-out bond strength in comparison to Biodentine at the first 24 hours [16].

Although manufactures propose that Biodentine is ideal for the repair of perforations and that setting time is a crucial factor, there is no study testing this. Thus the purpose of this study was to evaluate the sealing ability and marginal adaptation of 4 different sealing materials, three of them exhibiting very short or minor setting time. Two of the tested materials were a civil engineering material which is a very fast setting Portland cement with setting time of 1 minute which is used for instant leak repairs, and a light cured glass ionomer lining cement.

\section{Materials and Methods}

Eighty-four, recently extracted, multirooted upper permanent human molars, with no/minimal caries and fully developed, nonfused roots were used. The selection was based on the degree of the root separation so as the furcal area to be visible enough. Immediately after extraction the roots of each tooth were cleaned of soft tissues or bone remnants with periodontal curettes, disinfected with $\mathrm{NaOCl} \mathrm{3 \%}$ for 10 minutes and stored in normal saline solution until usage. They were visually inspected under magnification, discarding teeth with cracks, open apices or root caries.

Access cavities were prepared with a round diamond bur using high-speed handpiece under copious irrigation with water spray. The root canal system was cleaned and shaped according to the Step-back method using K-files and Gate Glidden drills. Sodium hypochlorite solution ( $\mathrm{NaOCl}$ ) 3\% was used as the irrigant. After drying the prepared root canals with paper points, AH Plus sealer (Densply-De Trey, Konstanz, Germany) was placed within the canals and they were filled with Gutta-percha using lateral condensation technique.

The outer surface of the roots was covered with two layers of nail varnish in order to prevent dye penetration from open tubules, minor dentine defects or lateral canals, with great assiduity to the furcation area. The pulp chamber floor was perforated in the middle with a \#4 round bur in a low-speed handpiece and constant water spray irrigation the teeth were rinsed with water and dried with air. The width of perforation corresponded to the diameter of the bur and the depth was dependent on the dentine-cementum thickness from the pulp chamber floor to the furcation area. Eighty teeth were randomly divided into four groups (G1-G4) of 20 teeth each and a further 4 teeth served as controls. Two teeth that were perforated but not repaired served as positive controls. Another two teeth that were not perforated served as negative controls.

In order to simulate clinical conditions all teeth were embedded approximately to the level of cementoenamel junction into a moistened, with distilled water, flower sponge.

The following materials were used to repair the perforations:

- MTA-Angelus (Angelus, Curitiba, Parana, Brazil) 
- Biodentine (Septodont, Saint-Maur-des-fosses Cedex, France)

- GC Fuji Lining Paste Pack (GC Europe)

- Aquafix (ISOMAT S.A., Thessaloniki, Greece)

\subsection{Repair of the Perforations}

In G1, MTA-Angelus was mixed according to the manufacturer's instructions, to produce a homogeneous paste. The material was placed in the perforation with MAP System (Master Apical Placement, Produits Dentaires, Switzerland) and compacted with Schilder pluggers (Hu Friedy, Chicago, IL, USA). A cotton pellet moistened with saline was placed in the pulp chamber over the MTA surface for 72 hours. After this period of time, the cotton pellet was removed and the access cavity was filled with IRM (Densply-DeTrey, Konstanz, Germany).

In G2, Biodentine was mixed according to the manufacturer's instructions until ideal consistency was achieved. The material was collected from the capsule, placed in the perforations with a spatula and slightly condensed with Amalgam pluggers and allowed to set for 12 minutes. After the proper setting of Biodentine has occurred, the access cavity was immediately filled as mentioned above.

In G3, the GC Fuji Lining Paste Pak was mixed on a glass slab using a metal spatula to a homogeneous consistency. With the use of a syringe the material was applied directly into the defect. The material was light cured for 20sec with a LED light curing device for every $2 \mathrm{~mm}$ placement of material.

In G4, the powder of Aquafil Portland cement was mixed with Water for Injection (Fresenius Kabi Hellas) to produce a homogeneous paste to a consistency similar to MTA-Angelus, according to the manufacturer. The Portland cement was placed in the perforation defect with an amalgam carrier, compacted gently with an amalgam plugger and pressed constantly with a wet cotton pellet for 1minute, according to the manufacturer's instructions. The access cavity was immediately filled as in the previous groups. One operator carried out all experimental procedures.

After the sealing of the access cavities with the IRM, the crowns were covered with two layers of nail varnish. The teeth were left for 28 days in the moistened sponge. Then they were removed and their outer surface was carefully cleaned from sponges' remnants with cotton pellets. The furcation area was inspected in detail so as to evaluate marginal adaptation and/or extrusion of the material using stereomicroscope under magnification $(\times 10)$ (Karl Kaps D-35614 Asslar, Germany).

\subsection{Preparation of Samples-Analysis}

The teeth were immersed in basic fuchsine $1 \%$ for 48 hours and then rinsed under running water. e After that, the teeth crown were sectioned longitudinally using diamond-coated disk (Macrotome 2, Metals research limited, Cambridge, England) and undergone surface polishing with Polisher Ecomet ${ }^{\circledR}$ III Grinder (Buehler Ltd, Illinois, USA) under constant irrigation of distilled water. Measurement of dye penetration between the dentinal walls and the restorative material was then carried out. The sectioned teeth were examined under magnification $\times 20$ using Leica 480 Steromicroscope (Leica Microsystems, Wetzlar, Germany). The actual values of dye penetration were calculated from the outer margin of the perforation cavity to the level of the pulpal floor by 3 investigators by using the CliniView 9.3 program (Instrumentarium Dental, Tuusula, Finland). The investigators were calibrated in a small sample of teeth for inter-examiner agreement. The data were subjected to statistical analysis One Way ANOVA (level of significance $<0.05$ ).

\section{Results}

It is interesting that all specimens exhibited microleakage. One specimen was excluded from the study because of fracture during the sectioning procedure (from Portland cement group). In all other specimens clear staining was seen between the main filling and the perforation cavity walls. The teeth of the positive control group showed massive dye penetration to the pulp chamber, whereas no evidence of microleakage occurred in the negative control group.

The statistical analysis of the results (Table 1) showed that perforations restored with MTA exhibited the least microleakage (Figure 1) with statistically significant difference among the other three groups $(\mathrm{p}<0.05)$. The worst sealing ability was observed in the teeth restored with Aquafix Portland cement. No statistically 
Table 1. Means and standard deviations of calculates marginal dye leakage for restorative materials.

\begin{tabular}{ccc}
\hline Material & Sample size & Mean value $\% \pm$ SD \\
MTA & 20 & $7.07 \pm 2.56^{\mathrm{a}}$ \\
Biodentine & 20 & $19.86 \pm 8.67^{\mathrm{b}}$ \\
GC Fuji Lining paste & 20 & $16.92 \pm 9.7^{\mathrm{b}}$ \\
Portland cement & $19^{*}$ & $33.43 \pm 11.23^{\mathrm{c}}$ \\
Positive controls & 2 & 100 \\
Negative controls & 2 & 0 \\
\hline
\end{tabular}

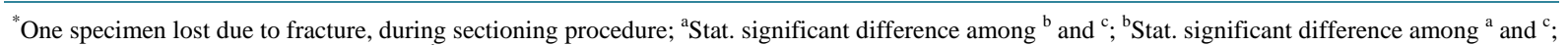
${ }^{\mathrm{c}}$ Stat. significant difference among ${ }^{\mathrm{a}}$ and ${ }^{\mathrm{b}}$.

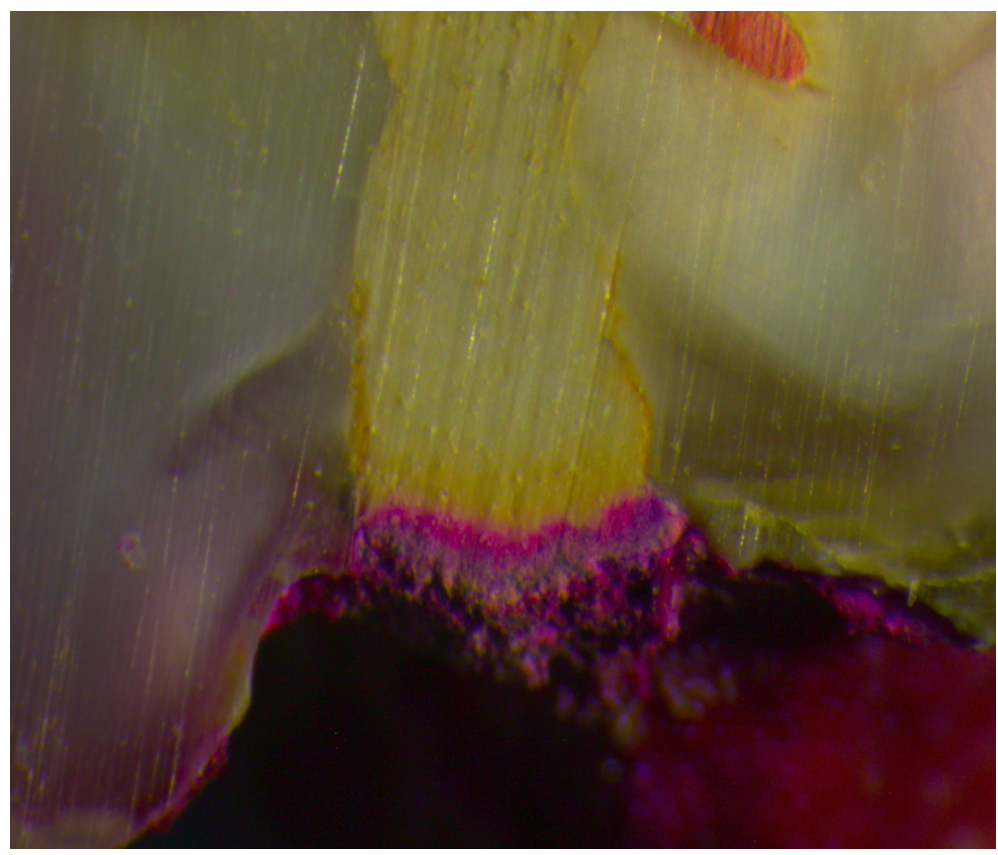

Figure 1. Perforation filled with MTA. Notice the good adaptation of the material to the irregularities of the perforation defect.

significant difference was found between the groups of Biodentine (Figure 2, Figure 3) and FC Fuji Lining Paste $(\mathrm{p}=0.066)$ (Figure 4).

As far as the marginal adaptation and the extrusion is concerned, Aquafix Portland cement exhibits the worst results (Figure 5), as it was always extruded far beyond the perforation cavity margins.

\section{Discussion}

The results demonstrated that MTA used as a restorative material for perforations in the pulp chamber floor, exhibited statistically significant better sealing behavior in comparison to the other materials.

In the present study, the dye penetration method was selected for the evaluation of the microleakage along the surface of the perforation cavity and the restorative material. In the literature various types of dyes have been used to evaluate material's sealing ability, including methylene blue, fuchsin, rhodamine B, silver nitrate, India ink and Pelikan ink. In a previous study a discoloration effect of MTA on methylene blue dye was observed [17]. However, a similar discoloration effect did not happen when Basic fuchsin solution 1\% is used [18] [19]. We did not select bacterial leakage models since MTA exerts antibacterial effects, nor we use the fluid transport mode since it cannot be performed reliably in perforation models. 


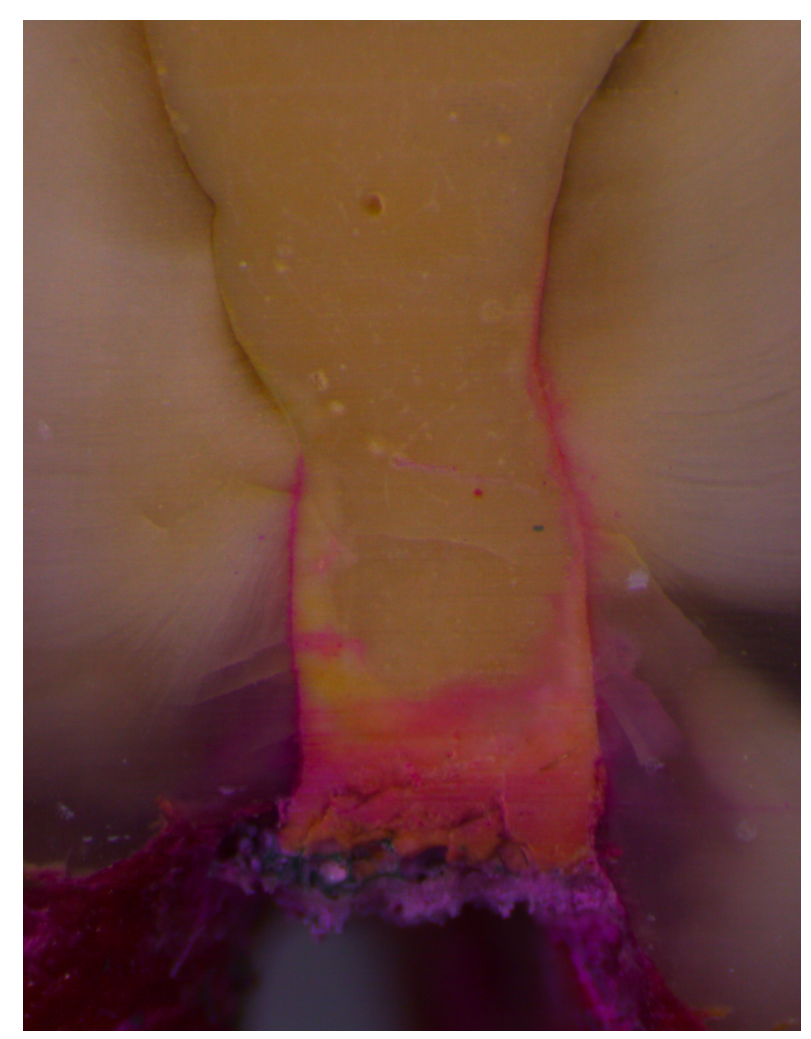

Figure 2. Restoration with Biodentine: there can be seen obvious cracks and abnormalities in the mass of the filling material, combined with significant microleakage.

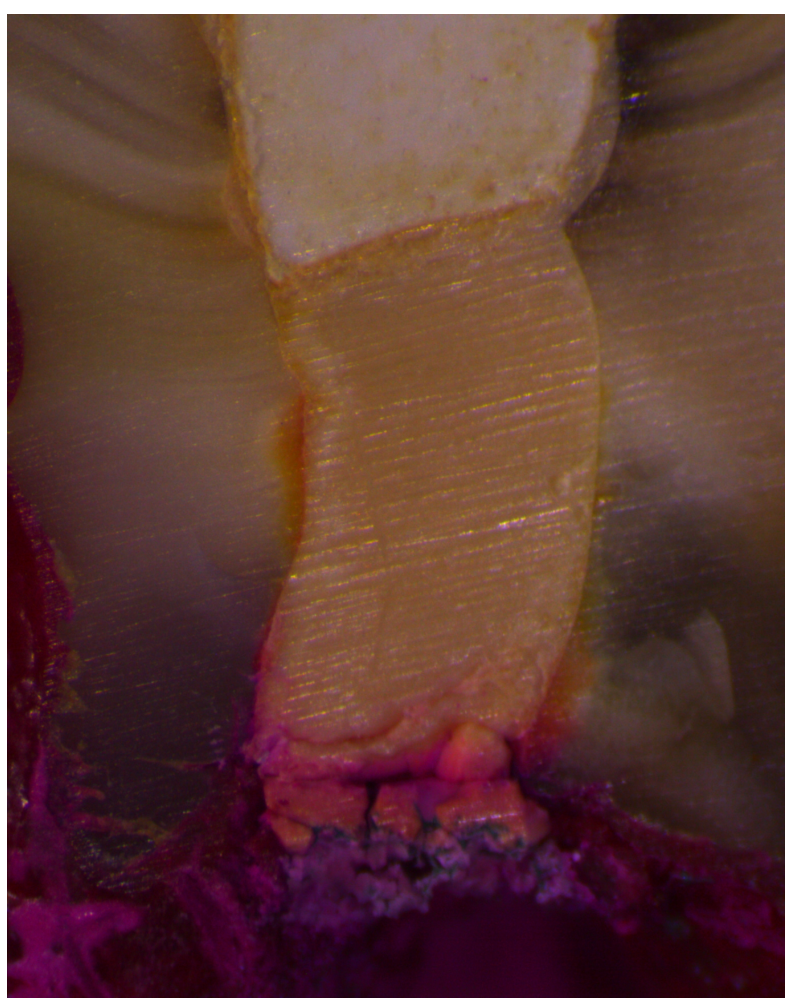

Figure 3. Rerforation cavity filled with Biodentine. 


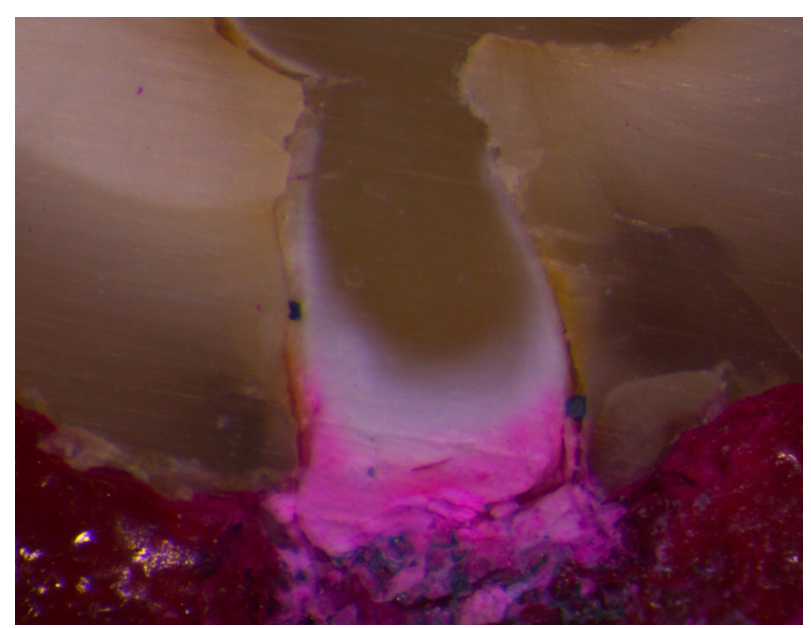

Figure 4. Perforation filled with Fuji LC Lining Paste. The alteration in materials color (more grayish) is evident suggesting a false polymerization possibly due to the presence of moisture.

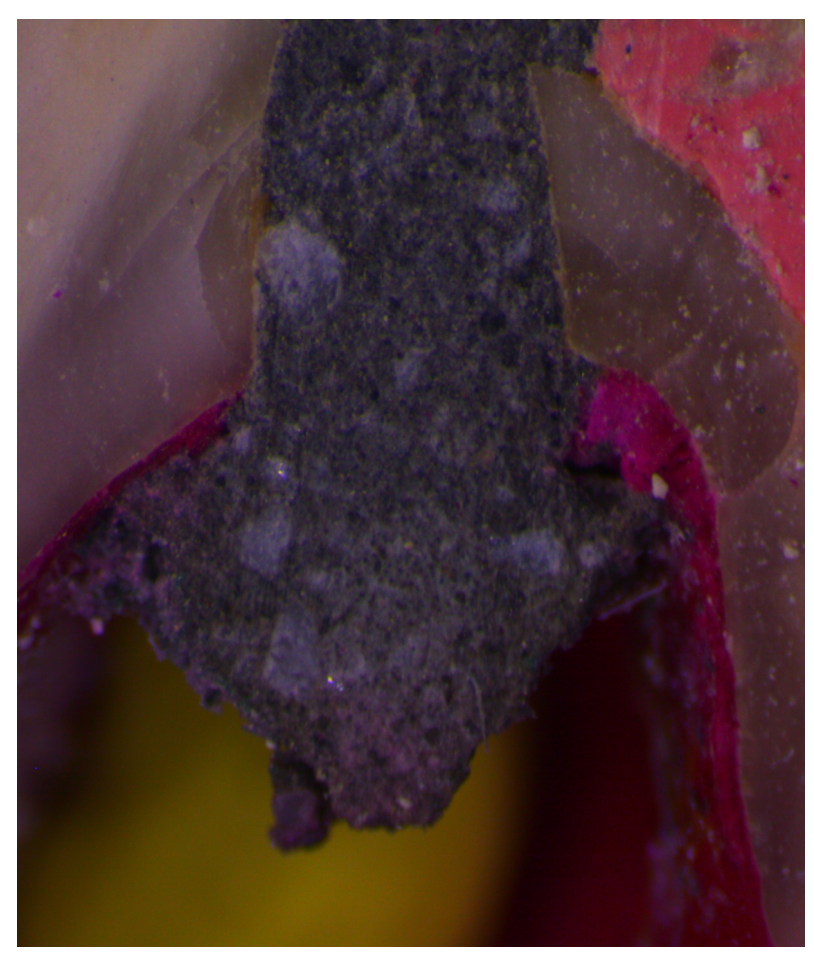

Figure 5. Rerforation defect restored with Aquafix Portland cement showed massive extrusion to furcation area.

MTA is a mixture of refined Portland cement and bismuth oxide, and is reported to contain trace amounts of Silicon Dioxide $\left(\mathrm{SiO}_{2}\right)$, Calcium Oxide (CaO), Magnesium Oxide (MgO), Potassium Sulfate $\left(\mathrm{K}_{2} \mathrm{SO}_{4}\right)$ and Sodium Sulfate $\left(\mathrm{Na}_{2} \mathrm{SO}_{4}\right)$. MTA poses two important clinical features, a) it sets in the presence of moisture e.g. tissue fluids [20]-[22], and b) it exerts vast antimicrobial action due to its alkaline $\mathrm{pH}$ (approximately $\mathrm{pH}=12$ ) [23]. This high $\mathrm{pH}$ is probably due to the existence of calcium oxides in the composition of the material [24]. The material's setting process is described as a hydration reaction of tricalcium silicate and dicalcium silicate which the latter is being responsible for the development of the material strength [25]. MTA's compressive strength and displacement resistance show increasing levels for up to 21 days in the presence of moisture, while 
its microhardness and hydration behavior seems to be affected by the low $\mathrm{pH}$ of the inflammatory environments [16] [26]. However, the main drawbacks of MTA include potential presence of toxic elements in the final product, difficulty in handling, long setting time and high material cost. The potential discoloration of hard tissues is still present even with the use of White ProRoot MTA and White MTA-Angelus, as both of them contain minimum amounts of iron and manganese [27].

Biodentine is based in an "in-house synthesized" Tricalcium Silicate to guarantee high purity. Adding calcium chloride $\left(\mathrm{CaCl}_{2}\right)$ to the liquid component accelerates the system, therefore decreasing of the liquid content in the system decreases the setting time to harden within 9 to 12 minutes. The addition of hydrosoluble polymer systems described as "water reducing agents" or super plasticizers, helps in maintaining the balance between low water content and consistency of the mixture [14]. The powder mainly consists of tri-calcium silicate (C3S), di-calcium silicate, calcium carbonate and oxide, iron oxide and zirconium oxide for radiopacity.

The material exhibits great biological properties, similar to MTA levels, such as biocompatibility and minimum toxicity [15]. According to the manufacturer, Biodentine ${ }^{\mathrm{TM}}$ exhibits lower porosity than ProRoot ${ }^{\circledR}$ MTA and has higher compressive strength in the first hour period. A recent study found that in the first 24 hours period MTA shows/exhibits reduced push-out bond strength in comparison to Biodentine [16]. The material's mechanical strength is improving over time and reaches more than $200 \mathrm{MPa}$ at $24 \mathrm{~h}$, a value far beyond of that of the most glass ionomer cements. As far as microleakage is concerned, our findings are not in agreement with those reported by the manufacturer. In our study, MTA exhibits excellent adaptation to the external margins of the perforation cavities, comparing to Biodentine and hence Biodentine showed statistically significant worse sealing ability. This is may be due to the different consistency of the tested materials. After mixing, MTA has a paste consistency which enables the material to flow laterally when a minimal resistance is met from the periodontal tissues (flower sponge in our study). However, Biodentine after mixing in the vibrator machine has a thicker consistency, resulting in handling and condensation problems (Figure 2), making the use of the plastic spatula the only effective delivery method. Thus, the higher percentage of microleakage can be attributed to the delivery method, which does not allow precise and controlled placement of the putty sealing material in the perforation cavity.

Perforations repaired with Fuji GC Lining LC Paste exhibited a significant dye penetration. We decided to use Fuji Lining Paste for furcation perforation repair because is a resin-modified light-cured glass ionomer cement, which have been found to exhibit an expansion after setting, possibly increasing the sealing ability of the material [28] [29]. As this product is light-cured within 20 seconds, one may assume that it will not dramatically be affected by the moisture of the periodontal tissues. In a previous study [9], another glass ionomer material (Vitremer) was used for the same reason but proved to be ineffective in sealing furcation perforations. According to the manufacturer, Fuji Lining LC paste has improved mechanical properties. It adheres chemically to dentin in the presence of moisture, without the need for conditioning, and exhibits greater tensile bond strength than traditional glass ionomers. Unlike powder/liquid liners which can be fiddly and time-consuming to use, the Paste Pak dispenser is quick and precise. Mixing time to the ideal liner consistency it takes only 10 seconds and unlike mixing powder/liquid material, the final product is free of air bubbles. After the mixing procedure, the cement inserted in the perforation cavities and was light-cured for 20 seconds. However, our results showed a high microleakage suggesting a false polymerization possibly due to the presence of moisture, despite the fact that we have used a dual-cured cement. The light cannot be transmitted effectively in the perforation defect and due to the presence of moisture the polymerization cannot be achieved effectively. This is supported by the alteration in materials color (more grayish) in the side facing the wet flower sponge (Figure 4). This finding is in agreement with a previous study [30] where significant changes in the properties of similar resin-modified glass-ionomer cements were reported in aqueous and neutral media.

Another material tested for its sealing ability is a commercial Portland cement product. Aquafix is an instant setting Portland cement, used for the rapid repair of pressure leaks and seepage. Previous reports have demonstrated that MTA and Portland cement are biocompatible [22]-[33]. Both materials contain calcium oxide that forms calcium hydroxide when mixed with water. The reaction of the calcium hydroxide and the carbon dioxide from the pulp tissue produces calcite crystals [34]. Seux [35] concluded that their findings strongly support the role of calcite crystals and fibronectin as an initiating step in the formation of a hard tissue barrier. Furthermore, it has been suggested that their physical properties could also be similar. Aquilina [36] supported this opinion when it was demonstrated that accelerated Portland cement had good sealing ability and adequate physical and mechanical properties for a restorative material. Moreover, De-Deus [37] reported that the leakage patterns 


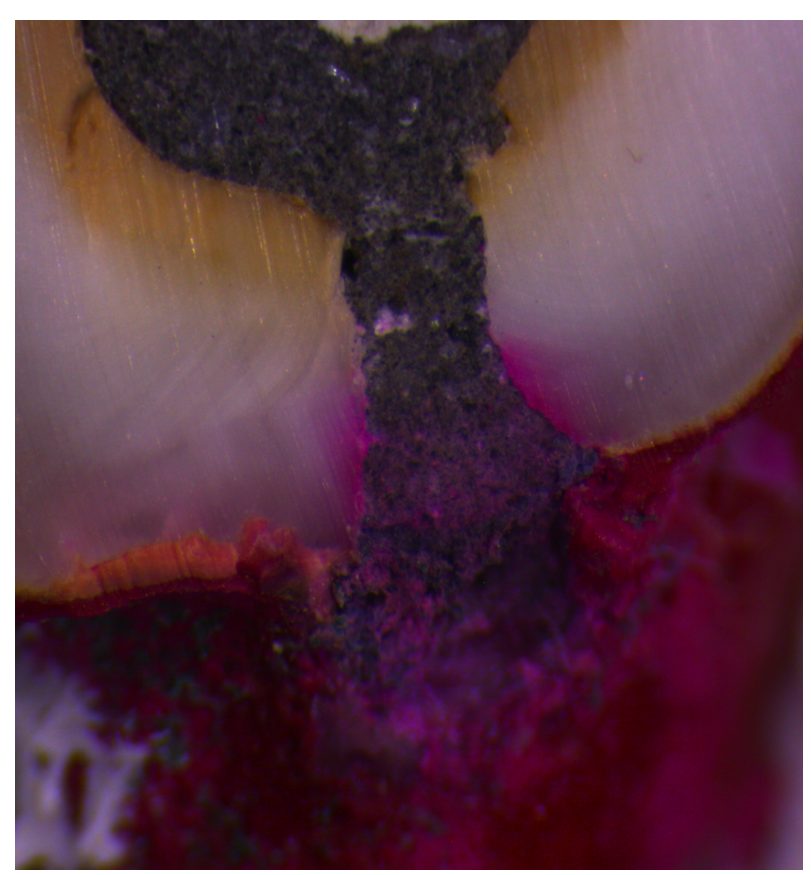

Figure 6. Aquafix Portland cement has very large participles which may explain the mass microleakage.

Pro-Root MTA and Portland cement in furcation repairs were similar over a period of 50 days, using a polymicrobial leakage model. A reason for the difference in the results is the different leakage model used in the two studies. As illustrated in Figure 6, the Portland cement used in our study has very large particles and always extruded into the periodontal tissues which may explain the mass microleakage. This observation can be explained by the fact that our study tests a different type of Portland cement, that has not been studied before in the repair of furcal perforations, which sets instantly and has different texture. This extrusion was present in all of our speciments despite the gentle handling and condensation of the material in the defects. Moreover, the extruded material had a rough surface and in a clinical situation it may mechanically irritate the periodontal tissues.

In our study, the results are expressed by calculating the percentage of dye penetration in relation to the perforation walls since depth of the perforation cavities is an uncontrolled variable dependent on the dentine-cementum thickness of each tooth. Furthermore, in clinical conditions such differences in depth may be even greater assuming that perforations are commonly result from excessive grinding of pulpal floor in an effort to locate calcified root canal orifices.

\section{Conclusions-Clinical Significances}

Under the conditions of this laboratory evaluation, MTA is still the material of choice for the repair of furcation perforations among other with significantly shorter or minimum setting time, such as Biodentine, resin-modified glass ionomer cements and Portland cement. Thus, setting time is not a crucial factor for the longevity and efficacy of the sealing.

Although, taking into account the high cost of MTA, Biodentine can be used as a potential alternative for the repair of furcation perforations due to its biocompatibility.

\section{Acknowledgements}

Authors deny any conflicts of interest related to this study.

\section{References}

[1] Sinai, I. (1977) Endodontic Perforations: Their Prognosis and Treatment. Journal of the American Dental Association, 95, 90-95. 
[2] Jew, R., Weine, F. and Keen, J. (1982) A Histologic Evaluation of Periodontal Tissues Adjacent to Root Perforations Filled with Cavit. Oral Surgery, Oral Medicine, Oral Pathology, Oral Radiology, and Endodontology, 54, 124-135. http://dx.doi.org/10.1016/0030-4220(82)90427-3

[3] Lemon, R. (1992) Nonsurgical Repair of Perforation Defects. Dental Clinics of North America, 36, 349-457.

[4] Pitt-Ford, T.R., Torabinejad, M., Mckentry, D.J., Hong, C.U. and Kariyawasam, S.P. (1995) Use of MTA for Repair of Furcal Perforations. Oral Surgery, Oral Medicine, Oral Pathology, Oral Radiology, and Endodontology, 79, 756-772. http://dx.doi.org/10.1016/S1079-2104(05)80313-0

[5] Yildirim, T., Gencoglu, N., Firat, I., Perk, C. and Guzel, O. (2005) Histological Study of Furcation Perforation Treated with MTA or Super-EBA in Dog's Teeth. Oral Surgery, Oral Medicine, Oral Pathology, Oral Radiology, and Endodontology, 100, 120-124. http://dx.doi.org/10.1016/j.tripleo.2004.09.017

[6] El Deeb, M.E., El Deeb, M., Tabibi, A. and Jensen, J.R. (1982) An Evaluation of the Use of Amalgam, Cavit \& Calcium Hydroxide in the Repair of Furcation Perforations. Journal of Endodontics, 8, 459-466. http://dx.doi.org/10.1016/S0099-2399(82)80151-9

[7] Fischer, E.J., Arens, D.E. and Miller, C.H. (1998) Bacterial Leakage of MTA as Compared with Zinc-Free Amalgam, IRM and Super-EBA as a Root-End Filling Material. Journal of Endodontics, 24, 176-179. http://dx.doi.org/10.1016/S0099-2399(98)80178-7

[8] Alhadainy, H.A. and Hinel, V.T. (2003) Comparative Study of the Sealing Ability of Light-Cures versus Chemically Cures Materials Placed into Furcation Perforations. Oral Surgery, Oral Medicine, Oral Pathology, Oral Radiology, and Endodontology, 76, 338-342. http://dx.doi.org/10.1016/0030-4220(93)90264-5

[9] Tsatsas, D., Meliou, E. and Kerezoudis, N.P. (1995) Sealing Effectiveness of Materials Used in Furcal Perforation in Vitro. International Dental Journal, 55, 133-141. http://dx.doi.org/10.1111/j.1875-595X.2005.tb00310.X

[10] Torabinejad, M., Smoth, P.W., Kettering, J.D. and Pitt Ford, T.R. (1995) Comparative Investigation of Marginal Adaptation of Mineral Trioxide Aggregate and Other Commonly Used Root-End Filling Materials. Journal of Endodontics, 21, 295-299. http://dx.doi.org/10.1016/S0099-2399(06)81004-6

[11] Sluyk, S.K., Hoon, P.C. and Hartwell, G.R. (1998) Evaluation of Setting Properties and Retention Characteristics of Mineral Trioxide Aggregate When Used as a Furcation Perforation Repair Material. Journal of Endodontics, 24, 768771. http://dx.doi.org/10.1016/S0099-2399(98)80171-4

[12] Torabinejad, M. and Parirokh, M. (2010) Mineral Trioxide Aggregate: A Comprehensive Literature Review-Part II: Leakage and Biocompatibility Investigations. Journal of Endodontics, 36, 190-202. http://dx.doi.org/10.1016/j.joen.2009.09.010

[13] Torabinejad, M., Hong, C.V., McDonald, F. and Ford, T.R.P. (1995) Physical and Chemical Properties of a New RootEnd Filling Material. Journal of Endodontics, 21, 349-353. http://dx.doi.org/10.1016/S0099-2399(06)80967-2

[14] Septodont, R \& D Department, Biodentine, Active Biosilicate Technology, Scientific File.

[15] Zhou, H., Shen, Y., Wang, Z., Li, L., Zheng, Y.F., Häkkinen, L. and Haapasalo, M. (2013) In Vitro Cytotoxicity Evaluation of a Novel Root Repair Material. Journal of Endodontics, 39, 478-483. http://dx.doi.org/10.1016/j.joen.2012.11.026

[16] Aggarwal, V., Singla, M., Miglani, S. and Kohli, S. (2013) Comparative Evaluation of Push-Out Bond Strength of ProRoot MTA, Biodentine, and MTA Plus in Furcation Perforation Repair. Journal of Conservative Dentistry, 16, 462465. http://dx.doi.org/10.4103/0972-0707.117504

[17] Wu, M.K., Kontakiotis, E.G. and Wesselink, P.R. (1998) Decoloration of 1\% Methylene Blue Solution in Contact with Dental Filling Materials. Journal of Dentistry, 26, 585-589. http://dx.doi.org/10.1016/S0300-5712(97)00040-7

[18] Meliou, H., Karoni, C., Chakmakchi, M. and Kerezoudis, N.P. (2005) Sealing Effectiveness of White ProRoot MTA. Odontostomatol Progress, 59, 372-381.

[19] Nikoloudaki, G., Meliou, H. and Kerezoudis, N.P. (2012) Comparison of Sealing Effectiveness of MTA and Biodentine in Furcation Perforation. Odontostomatol Progress, 66, 454-464.

[20] Fridland, M. and Rosato, R. (2003) Mineral Trioxide Aggregate (MTA) Solubility and Porosity with Different Waterto-Powder Ratios. Journal of Endodontics, 29, 814-817. http://dx.doi.org/10.1097/00004770-200312000-00007

[21] Sarkar, N.K., Caidedo, R., Ritwi, P., Moiseyeva, R. and Kawashima, I. (2005) Physicochemical Basis of the Biologic Properties of Mineral Trioxide Aggregate. Journal of Endodontics, 21, 731-738.

[22] Camilleri, J. and Ford, T.R.P. (2006) Mineral Trioxide Aggregate: A Review of Constituents and Biological Properties of the Material. International Endodontic Journal, 39, 747-754. http://dx.doi.org/10.1111/j.1365-2591.2006.01135.x

[23] Al-Hazaimi, K., Al-Shalan, T.A., Naghshbandi, J., Oglesby, S., Simon, J.H. and Rotstein, I. (2006) Antibacterial Effect of Two MTA Preparations against Enterococcus faecalis and Streptococcus sanguis in Vitro. Journal of Endodontics, 32, 1053-1056. http://dx.doi.org/10.1016/j.joen.2006.06.004 
[24] Koh, E.T., Torabinejad, M., Ford, T.R.P., Brady, K. and McDonald, F. (1997) Mineral Trioxide Aggregate Stimulates a Biological Response in Human Osteoblasts. Journal of Biomedical Materials Research, 37, 432-439. http://dx.doi.org/10.1002/(SICI)1097-4636(19971205)37:3<432::AID-JBM14>3.0.CO;2-D

[25] Dammaschke, T., Gerth, H.U., Zuchner, H., Brady, K. and McDonald, F. (2005) Chemical and Physical Surface and Bulk Material Characterization of White ProRoot MTA and Two Portland Cements. Dental Materials, 21, 731-738. http://dx.doi.org/10.1016/j.dental.2005.01.019

[26] Namazikhah, M.S., Nekoofar, M.H., Sheykhrezae, M.S., Salariyeh, S., Hayes, S.J., Bryant, S.T., Mohammadi, M.M. and Dummer, P.M. (2008) The Effect of $\mathrm{pH}$ on Surface Hardness and Microstructure of Mineral Trioxide Aggregate. International Endodontic Journal, 41, 108-116.

[27] Asgary, S., Parirokh, M., Eghabal, M.J. and Brink, F. (2005) Chemical Differences between White and Gray Mineral Trioxide Aggregate. Journal of Endodontics, 31, 101-103. http://dx.doi.org/10.1097/01.DON.0000133156.85164.B2

[28] Attin, T., Buchalla, W., Kiebassa, A.M. and Helwig, E. (1995) Curing Shrinkage and Volumetric Changes of ResinModified Glass Ionomer Restorative Materials. Dental Materials, 11, 359-362. http://dx.doi.org/10.1016/0109-5641(95)80035-2

[29] Kanchanavasita, W., Antice, H.M. and Pearson, G.J. (1997) Water Absorption Characteristics of Resin-Modified Glass-Ionomer Cements. Biomaterials, 18, 343-349. http://dx.doi.org/10.1016/S0142-9612(96)00124-X

[30] Watts, D.C., Kisumbi, B.K. and Toworfe, G.K. (2000) Dimensional Changes of Resin/Ionomer Restoratives in Aqueous Neutral Media. Dental Materials, 16, 89-96. http://dx.doi.org/10.1016/S0109-5641(99)00098-6

[31] Wucherpfenning, A.L. and Green, D.B. (1999) PR 40 Mineral Trioxide vs. Portland Cement: Two Biocompatibile Filling Materials. Journal of Endodontics, 25, 308. http://dx.doi.org/10.1016/S0099-2399(99)80264-7

[32] Estrela, C., Bammann, L.L., Estrela, C.R., Silva, R.S. and Pécora, J.D. (2000) Antimicrobial and Chemical Study of MTA, Portland Cement, Calcium Hydroxide Paste, Sealapex and Dycal. Brazilian Dental Journal, 11, 3-9.

[33] De Deus, G., Ximenes, R., Gurgel-Filho, E., Plotkowski, M.C. and Coutinho-Filho, T. (2005) Cytotoxicity of MTA and Portland Cement on Human ECV 304 Endothelial Cells. International Endodontic Journal, 38, 604-609. http://dx.doi.org/10.1111/j.1365-2591.2005.00987.x

[34] Holland, R., De Souza, V., Nery, M.J., Faraco Jr., I.M., Bernabé, P.F., Filho, J.A.O. and Dezan Jr., E. (2001) Reaction of Rat Connective Tissue to Implanted Dentin Tube Filled with Mineral Trioxide Aggregate, Portland Cement or Calcium Hydroxide. Brazilian Dental Journal, 12, 3-8.

[35] Seux, D., Couble, M.L., Hartmann, D.J., Gauthier, J.P. and Magloire, H. (1991) Odontoblast-Like Cytodifferentiation of Human Dental Pulp Cells in Vitro in the Presence of a Calcium Hydroxide-Containing Cement. Archives of Oral Biology, 36, 117-128. http://dx.doi.org/10.1016/0003-9969(91)90074-5

[36] Aquilina, J.W. (1999) The Physical Properties of Accelerated Portland Cement. M.Sc. Project Report, University of London, London.

[37] De Deus, G., Petruccelli, V., Gurgel-Filho, E. and Coutinho-Filho, T. (2006) MTA versus Portland Cement as Repair Material for Furcal Perforations: A Laboratory Study Using a Polymicrobial Leakage Model. International Endodontic Journal, 39, 293-298. http://dx.doi.org/10.1111/j.1365-2591.2006.01096.x 
Scientific Research Publishing (SCIRP) is one of the largest Open Access journal publishers. It is currently publishing more than 200 open access, online, peer-reviewed journals covering a wide range of academic disciplines. SCIRP serves the worldwide academic communities and contributes to the progress and application of science with its publication.

Other selected journals from SCIRP are listed as below. Submit your manuscript to us via either submit@scirp.org or Online Submission Portal.
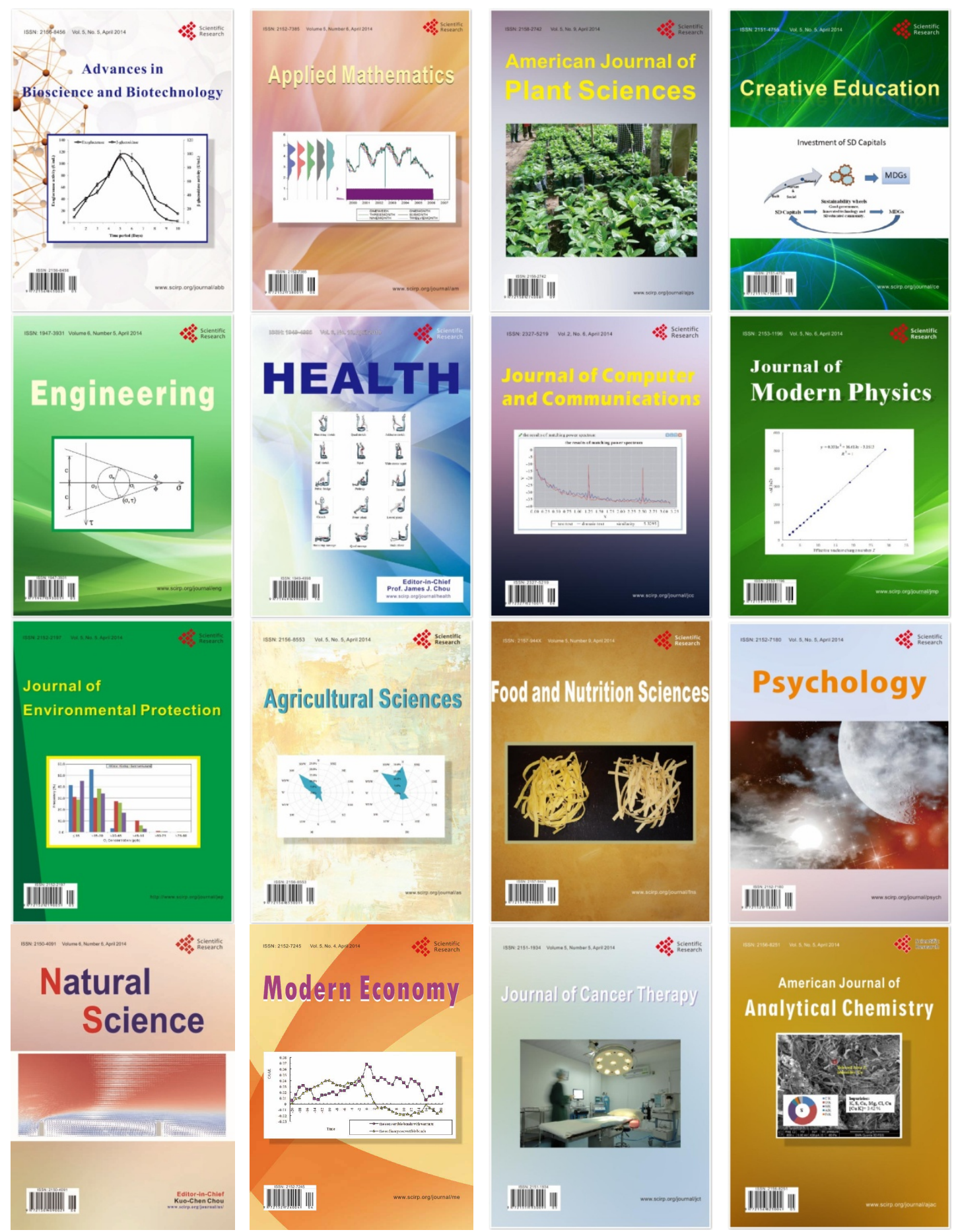